\title{
Preface to the Special Issue 52 (3): \\ BIOEXPLOIT: Exploitation of Natural Plant Diversity for the Pesticide-Free Production of Food
}

\author{
Aska Goverse • Paul C. Struik
}

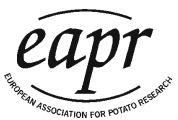

Published online: 28 July 2009

(C) EAPR 2009

The 17th Triennial Conference of the European Association for Potato Research (EAPR) was organized by the Romanian National Institute of Research and Development for Potato and Sugar Beet in Brasov, Romania, under the leadership of its director Dr Sorin Chiru. The theme of the conference was: "Potato in a Changing World". The programme included four workshops and one of these workshops was on the EU Framework 6 Integrated Project BIOEXPLOIT.

The EU Framework 6 Integrated Project BIOEXPLOIT started in 2005. Participants are from 45 (both public and private) laboratories. The basic objective of BIOEXPLOIT is to explore and exploit the natural biodiversity in the plant kingdom in order to advance the production of food in a pesticide-free manner. The programme deals with four crops (wheat, barley, tomato and potato) and with the pathogens Phytophthora infestans, Septoria tritici, Blumeria graminis, Puccinia spp. and Fusarium spp.

Together with EUCARPIA (the European Association for Research on Plant Breeding), the EAPR participates in BIOEXPLOIT by facilitating the dissemination of the results obtained in the project to the potato research community. The EAPR has done so in the past by publishing the special issue of Potato Research on the Canon of Potato Science (Struik et al. 2007) and the special issue on Late Blight and Genetic Modification (Struik 2008). The workshop in Brasov and this third special issue are proof of the continuation of the efforts to disseminate the results of BIOEXPLOIT.

\footnotetext{
A. Goverse

Project Staff Office, BIOEXPLOIT, Droevendaalsesteeg 1, 6708 PB Wageningen, The Netherlands

P. C. Struik $(\bowtie)$

Centre for Crop Systems Analysis, Wageningen University, P.O. Box 430, 6700 AK Wageningen, The Netherlands

e-mail: paul.struik@wur.nl
} 
In this special issue, we report on the preliminary results of the project as highlighted during the workshop in Romania. The BIOEXPLOIT project has four strategic objectives. These objectives include:

(i) understanding the molecular components involved in durable disease resistance,

(ii) exploring and exploiting the natural biodiversity in disease resistance,

(iii) accelerating the introduction of marker-assisted breeding and genetic engineering in the EU plant breeding industry, and

(iv) coordinating and integrating resistance breeding research, providing training in new technologies, disseminating the results, and transferring knowledge and technologies to the industry.

During the workshop, Aska Goverse presented an outline of the project and its objectives and approaches. The progress on the first objective was highlighted by Glenn Bryan in his contribution on sources of resistance genes for deployment against Phytophthora infestans and by Erik Slootweg in his presentation on the localization and structure-function relationships of R proteins in Solanum. Objective 2 was illustrated by Roel Hoekstra in his contribution, entitled "Exploring the natural biodiversity of potato (and wheat) for disease resistance". Ana Carrasco informed the audience about the progress relating to objective 3 in her contribution on markerassisted breeding for disease resistance. Finally Richard Visser underlined the importance of objective 4 by describing the need for new strategies in resistance breeding to combat late blight resistance making use of modern genetic engineering tools. The workshop was closed with a debate on the basis of six propositions.

These presentations and the debate are further elaborated in this special issue. We thank the contributors to the workshop and we keep good memories of the lively debate after the presentations.

The guest editors

\section{References}

Struik PC (ed) (2008) Special issue on late blight and genetic modification. Potato Res 51:1-99

Struik PC, Lommen WJM, Haverkort AJ, Storey RMJ (eds) (2007) The Canon of Potato Science. Potato Res 50:205-417 